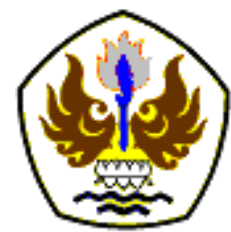

INFOMATEK

Volume 21 Nomor 2 Desember 2019

\title{
USULAN PREVENTIVE MAINTENANCE KOMPONEN KRITIS PADA MESIN HIGH PRESSURE PUMP DI PT.DIAN SWASETIKA SENTOSA DENGAN METODE GROUP REPLACEMENT
}

\author{
Ragil Pardiyono *), Tedi Hartanto \\ Program Studi Teknik Industri \\ Universitas Jenderal Achmad Yani Bandung
}

\begin{abstract}
Abstrak: PT Dian Swasetika Sentosa merupakan salah satu perusahaan yang bergerak di sektor pembangkit listrik tenaga uap. Dalam proses produksinya perusahaan ini memerlukan penggunaan air yang cukup banyak dengan kualitas yang bagus. Agar perusahaan tidak mengalami kerugian akibat biaya penggunaan air tersebut, maka perlu melakukan manajemen perawatan komponen mesin yang lebih baik untuk meminimasi kerugian yang diakibatkan oleh kerusakan mesin. Upaya yang dilakukan untuk meminimasi kerugian tersebut adalah dengan kebijakan perawatan secara berkala yaitu preventive maintenance sehingga diharapkan downtime yang dihasilkan pada mesin kecil. Model kebijakan yang digunakan adalah age replacement sebagai penentu umur pakai dari masing-masing komponen kritis dan group replacement sebagai penentu umur pakai satu kelompok pergantian dari komponen kritis tersebut, dengan tujuan memberikan jadwal pergantian mesin yang optimal yang meminimasikan downtime pada sehingga total biaya yang dikeluarkan minimum. Berdasarkan hasil penelitian, diperoleh jadwal pergantian optimal yaitu kelompok komponen kritis setiap 26 hari sekali dengan total nilai downtime 2,244 hari dari yang awalnya 3,453 hari, dari nilai downtime tersebut perusahaan dapat melakukan penghematan $35 \%$ /tahun.
\end{abstract}

Kata kunci: downtime, group replacement, perawatan, preventive maintenance

\section{PENDAHULUAN}

PT Dian Swasetika Sentosa merupakan salah satu perusahaan yang bergerak di sektor pembangkit listrik tenaga uap, dalam proses produksinya memerlukan penggunaan air yang cukup banyak dengan kualitas yang bagus. Water treatment plant adalah bangunan utama pengolahan air bersih, output dari pengolahan air yang diolah pada

*) ragilpardiyono@gmail.com

Pertama diterima : 19 Oktober 2019

Direvisi : 22 Oktober 2019

Disetujui untuk publikasi: 28 Oktober 2019 water treatment adalah air condensate. Air condensate adalah air input boiler yang digunakan agar proses pembakaran dapat terfluidasi secara sempurna sehingga menghasilkan uap. Dalam memproduksi air condensate, water treatment plant memiliki 20 mesin pengolahan air dengan sistem manajemen perawatan corrective maintenance, sistem ini mengakibatkan downtime yang tinggi pada mesin. Downtime yang tinggi ini menyebabkan proses produksi air condensate terhenti sehingga perusahaan 
harus menggunakan air alternatif untuk input boiler yaitu air softener dengan biaya chemical yang lebih mahal dari pada air condensate. Pemborosan yang telah selama bulan AprilDesember tahun 2017 adalah total penggunaan air softener selama 2017 sebanyak $44.800 \mathrm{~m}^{3}$ atau 448 jam dikalikan dengan selisih biaya penggunaan chemical air condensate dan air softener sebesar $\mathrm{Rp}$ 12.861.500,00. Sehingga total pemborosan pada bulan April-Desember tahun 2017 adalah Rp 5.761.952.000,00. Dalam mempertimbangkan hal ini perusahaan perlu melakukan manajemen perawatan komponen mesin yang lebih baik untuk meminimasi kerugian yang diakibatkan oleh kerusakan mesin.

\section{METODOLOGI}

Keandalan merupakan probabilitas bahwa sebuah unit akan memberikan kemampuan yang memuaskan untuk suatu tujuan tertentu dalam periode waktu tertentu ketika dalam kondisi lingkungan tertentu (Siagian dkk. [1]). Secara umum konsep keandalan dapat digambarkan dalam Bathtub Curve yang menjelaskan siklus hidup item/ komponen.

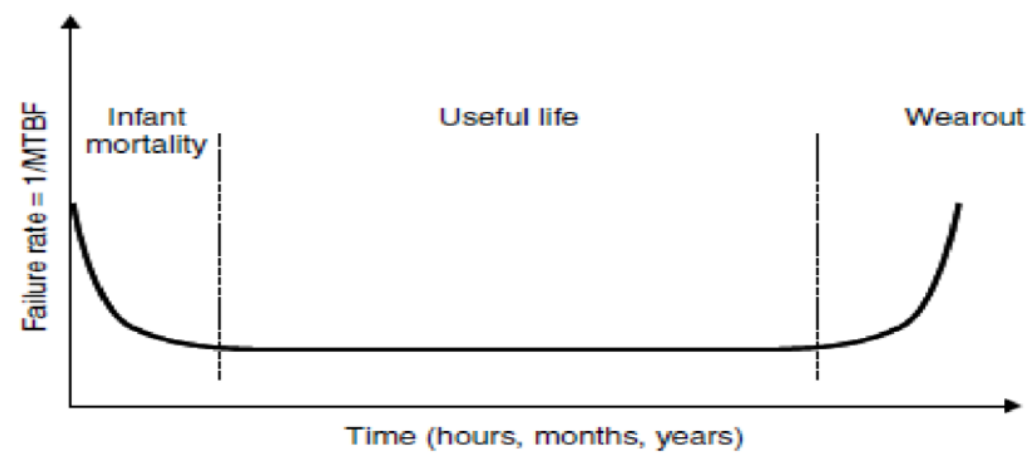

Gambar 1.

Bathtub Curve

Fungsi keandalan adalah fungsi yang berhubungan dengan waktu (waktu pengoperasian mesin) atau dalam kondisi operasi standar alat tidak akan mengalami kerusakan dan dapat beroperasi dengan baik (Utomo dkk. [2]). Secara statistik fungsi keandalan atau $\mathrm{R}(\mathrm{t})$ didefinisikan sebagai probabilitas dari komponen masih tetap berfungsi pada spesifikasi yang telah ditentukan pada saat $\mathrm{t}$, secara matematis dapat dinyatakan sebagai berikut :

$\mathrm{R}(\mathrm{t})=\mathrm{P}(\mathrm{x}>\mathrm{t})$ Dimana $\mathrm{x}$ adalah umur komponen.

Apabila $f(x)$ menyatakan fungsi kepadatan kemungkinan dan $F(x) d x$ menyatakan probabilitas dari komponen akan mengalami kegagalan pada interval $(x, x+\Delta x)$, dan jumlah probabilitas fungsi keandalan dan 
fungsi distribusi kumulatif sama dengan satu, maka didapatkan persamaan berikut :

$F(x)=P(X<t)$

Sehingga probabilitas untuk dapat beroperasi pada spesifikasi yang telah ditentukan atau fungsi keandalannya dapat dinyatakan secara matematis sebagai berikut :

$R(t)=1-F(x<t)$

$R(t)=\int_{\infty}^{\infty} f(x) d x$

$R(t)=\int_{\infty}^{\infty} f(t) d t-\int_{\infty}^{\infty} f(t) d t$

$R(t)=1-F(t)$

Laju kerusakan suatu mesin atau komponen pada saat $t$ adalah besarnya probabilitas bahwa mesin atau komponen tersebut akan mengalami kerusakan pada interval berikutnya. Sedangkan pada saat $t$ mesin atau komponen tersebut masih dalam keadaan baik.secara matematis fungsi lajunya kerusakan dapat diuraikan seperti dibawah ini

$$
\begin{aligned}
& r(t)=\lim _{\Delta t \rightarrow 0} \frac{R(t)-R(t+\Delta t)}{\Delta t R(t)} \\
& =\frac{1}{R(t)}\left(-\left(\frac{d}{d(t)}\right) R(t)\right. \\
& r(t)=\frac{f(t)}{r(t)}=\frac{f(t)}{1-F(t)}
\end{aligned}
$$

Apabila $r(t)$ meningkat sesuai dengan waktu, maka fungsi laju kerusakan menaik (increasing failure rute) dan sebaliknya, jika $r(t)$ menurun terhadap waktu maka disebut sebagai laju kerusakan menurun (decreasing failure rate). Dalam melaksanakan kebijakan perawatan terdapat beberapa distribusi kerusakan yang dapat digunakan,yaitu distribusi Weibull, distribusi Lognormal, distribusi Eksponensial, dan distribusi normal. Dalam mengidentifikasi distribusi dapat dilakukan dengan Index of Fit $(r)$ dan Goodness of Fit Test.Index of Fitterdiri dariProbability Plot dan Least-Square Curve Fitting (Muhammad [3]). Probability Plot dipakai untuk sampel kecil atau tidak lengkap, metode Least-Square Curve Fitting lebih baik dibanding Probability Plot. Perhitungan pada Metode Least-Square Curve Fitting yaitu:

$F\left(t_{i}\right)=\frac{l-0,3}{n+0,4}$

Keterangan :

$\mathrm{i}=$ data waktu ke-t

$\mathrm{n}=\mathrm{r}=$ jumlah data kerusakan

$=\frac{n \sum_{i=1}^{n} x_{i} y_{i}-\left(\sum_{i=1}^{n} x_{i}\right)\left(\sum_{i=1}^{n} y_{i}\right)}{\sqrt{\left[n \sum_{i=1}^{n} x_{i}^{2}-\left(\sum_{i=1}^{n} x_{i}\right)^{2}\right]}\left[n \sum_{i=1}^{n} y_{i}^{2}-\left(\sum_{i=1}^{n} y_{i}\right)^{2}\right]}$

Goodness of Fit Test dilakukan dengan cara membandingkan dua hipotesis yang berlawanan yaitu:

$\mathrm{H}_{0}$ : Data kerusakan atau perbaikan mendekati suatu distribusi tertentu. 
$\mathrm{H}_{1}$ : Data kerusakan atau perbaikan tidak menghampiri suatu distribusi tertentu.

Distribusi Eksponensial diuji dengan Uji Bartllet, Distribusi Normal dan lognormal dengan Uji Kolmogorov-Smirnov, serta Distribusi Weibull dengan Uji Mann's. Probability plot dan least-square curve fitting berguna untuk identifikasi kerusakan dan waktu perbaikan (Majid dkk [4]). Metode leastsquare curve fitting, distribusi yang nilai index of fit terbesar akan dilanjutkan ke uji Goodness of Fit Test. Rumus metode leastsquare curve fitting yaitu :

$F\left(t_{i}\right)=\frac{l-0,3}{n+0,4}$

Dimana :

$\mathrm{i}=$ data waktu ke-t

$\mathrm{n}=\mathrm{r}=$ jumlah data kerusakan

\section{Model Age Replacement}

Model age replacement adalah interval waktu penggantian komponen dengan memperhatikan umur pemakaian dari komponen. Model age replacement terdapat 2 siklus penggantian pencegahan seperti pada gambar berikut:

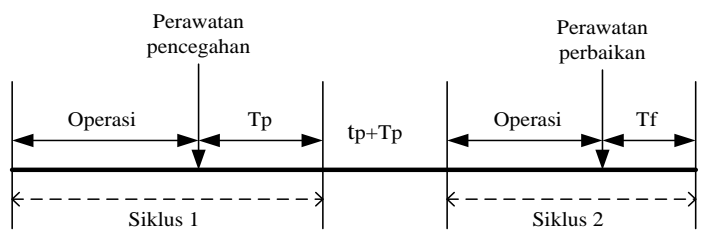

Gambar 2.

Model Age Replacement
Total downtime per unit waktu untuk penggantian pencegahan pada saat tp didenotasikan dengan D (tp) yaitu (Jardine dalam Putra dkk. [5]) :

$$
\mathrm{D}\left(t_{p}\right)=\frac{\text { Total ekpetasi downtime pergantian persiklus }}{\text { Ekspektasi panjang siklus }}
$$

Ekspektasi panjang siklus kondisi gagal juga merupakan penjumlahan dan downtime perbaikan kerusakan dengan interval rata-rata terjadinya kerusakan atau $M\left(t_{p}\right)$, dimana $M\left(t_{p}\right)$ $: M(t p)=\left(\frac{t p}{\alpha}\right)^{\beta}$.

Maka, rumus model penentuan interval penggantian adalah:

$\mathrm{D}\left(t_{p}\right)$

$=\frac{T_{p} \cdot R\left(t_{p}\right)+T_{f\left[1-R\left(t_{p}\right)\right]}}{\left.\left(t_{p}+T_{p}\right) \cdot R\left(t_{p}\right)+\left[M\left(t_{p}\right)+T_{f[1-R(} t_{p}\right)\right]}$

Dimana :

$T_{p} \quad=$ waktu untuk melakukan penggantian pencegahan

$T_{f} \quad=$ Waktu untuk melakukan penggantian kerusakan

$t_{p} \quad=$ Interval waktu perawatan pencegahan

$F_{(t)} \quad=$ Fungsi distribusi interval antar kerusakan yang terjadi

$\mathrm{R}\left(t_{p}\right)=$ Probabilitas terjadinya penggantian pencegahan pada saat $t_{p}$ 
$\mathrm{M}\left(t_{p}\right)=$ Waktu rata-rata terjadi kerusakan jika penggantian pencegahan dilakukan $t_{p}$

$\mathrm{D}\left(t_{p}\right)=$ Downtime persatuan waktu

\section{Model Block Replacement}

Komponen dari mesin kerap kali kedapatan rusak secara tiba-tiba dan ketika kerusakan terjadi harus segera diganti.Karena kerusakan tersebut tidak diharapkan dan tidak dapat diketahui secara tepat, maka sangat beralasan untuk mengasumsikan bahwa ongkos penggantian komponen yang rusak (failure replacement) lebih mahal dibandingkan penggantian karena pencegahan (preventive maintenance). Model penggantian pencegahan ini dilakukan pada suatu interval yang tetap sedangkan age replacement adalah model penggantian pencegahan yang dilakukan tergantung pada umur pakai dari komponen (Mutiara dkk. [6]). Tujuannya adalah menentukan interval waktu optimal antar penggantian pencegahan untuk meminimasi ekspetasi ongkos total penggantian per satuan waktu.



Gambar 3.

Kebijakan Block Replacement
Ekspetasi ongkos total per-satuan waktu dalam rangka penggantian pencegahan pada $t_{p}$ atau $D\left(t_{p}\right)$ adalah:

$\mathrm{D}\left(\mathrm{t}_{\mathrm{p}}\right)=\frac{\text { Ekpetasi ongkos total dalam Interval }\left(0, \mathrm{t}_{\mathrm{p}}\right)}{\text { panjang siklus }}$

Ekspetasi ongkos total dalam interval $\left(0, t_{p}\right)=$ $D_{p}-D_{r} \cdot H\left(t_{p}\right)$

Dimana $H\left(t_{p}\right)$ adalah ekspetasi jumlah kerusakan dalam interval $\left(0, t_{p}\right)$, jadi

$\mathrm{D}\left(t_{P}\right)=\frac{\mathrm{Dp}+\mathrm{Cf} \mathrm{H}(\mathrm{tp}}{t_{P}}$

\section{Model Group Replacement}

Model yang dikembangkan untuk masalah ini didasarkan pada asumsi bahwa kebijakan penggantian adalah untuk melakukan penggantian kelompok pada interval waktu yang tetap, dimana ada kemungkinan penggantian beberapa komponen dapat dilakukan pada saat bersamaan (Jardine dalam Sormin dkk. [7]).

Model persamaannya adalah sebagai berikut :

$\mathrm{D}\left(t_{P}\right)=\frac{\mathrm{N}\left(T_{g}\right)+\mathrm{NH}\left(t_{P}\right) T_{f}}{t_{P}}$

Keterangan :

$T_{p} \quad=$ waktu yang dibutuhkan untuk melakukan penggantian secara bersamaan;

$T_{f} \quad=$ biaya penggantian kegagalan;

$\mathrm{N} \quad=$ jumlah total adalah jumlah frekuensi dalam satu grup; 


$$
\begin{array}{r}
\mathrm{H}\left(t_{P}\right)=\text { jumlah yang diharapkan dari satu } \\
\text { item gagal dalam interval }\left(0, t_{P}\right) .
\end{array}
$$

\section{HASIL DAN PEMBAHASAN}

Biaya pemeliharaan perawatan mesin terbagi atas beberapa elemen meliputi komponenpengganti, teknisi, operator dan mesin. Adapun biaya-biaya tersebut adalah sebagai berikut, upah teknisi $R p$ 4.300.000/bulan, upah operatorRp 4.300.000/bulan, waktu kerja 22 Hari/bulan, Maka upah untuk Tenaga Kerja (jam/shift) adalah teknisi pemeliharaanRp 179.167/hari, operator menganggur Rp 179.167/hari. Biaya akibat mesin menganggur (Downtime)meliputi selisih biaya yang dikeluarkan antara air condensate dan air softener sebanyak $100 \mathrm{~m}^{3} / \mathrm{jam}$. Biaya downtime adalah sebesar $\mathrm{Rp} 19.292 .250$ - Rp $6.430 .750=\mathrm{Rp}$ 12.861.500.

Biaya pembelian komponen pengganti adalah biaya yang dikeluarkan dari harga komponen pengganti.Waktu perawatan adalah data waktu yang digunakan saat melakukan aktivitas perawatan mesin Berikut adalah harga komponen dan waktu perawatan:

Tabel 1.

Biaya Komponen Pengganti

\begin{tabular}{cccc}
\hline $\begin{array}{c}\text { Nama } \\
\text { Komponen }\end{array}$ & Harga Komponen & $\begin{array}{c}\text { Waktu failure maintenance } \\
\text { (Tf)(Hari) }\end{array}$ & $\begin{array}{c}\text { Waktu preventive } \\
\text { maintenance (Tp)(Hari) }\end{array}$ \\
\hline Pulley & Rp 659.250 & 0.158 & 0.048 \\
\hline Bearing & Rp 1.085 .400 & 0.131 & 0.039 \\
\hline Hydraulic & Rp 575.900 & 0.153 & 0.046 \\
\hline Piston & Rp 465.000 & 0.133 & 0.040 \\
\hline
\end{tabular}

Berdasarkan perhitungan distribusi untuk setiap komponen kritis didapat nilai index of fit terbesar pada distribusi weibull, maka distribusi terpilih untuk komponen semua komponen mesin high pressure pump. Pengujian distribusi interval dilakukan untuk membuktikan hasil perhitungan dari distribusi yang sudah terpilih. Dari hasil perhitungan terlihat bahwa $\mathrm{S}_{\text {hitung }}<\mathrm{S}_{\text {tabel, }}$ artinya $\mathrm{H}_{0}$ diterima, maka semua komponen berdistribusi weibull.
Setelah didapat distribusi terpilih yaitu weibull, maka parameter yang harus dicari untuk menentukan penggantian komponen adalah $\alpha$ dan $\beta$. Berikut adalah hasil dari rekapitulasi perhitungan uji man test dan parameter distribusi dari setiap komponen.

Penentuan jadwal perawatan dilakukan setelah didapat nilai parameter $\alpha$ dan $\beta$, tujuanya untuk mencari tanggal yang memiliki nilai downtime $\left(D_{\text {tp }}\right)$ yang minimum untuk 
melakukan aktivitas perawatan. Tabel 3 dari setiap komponen kritis. adalah hasil rekapitulasi pergantian komponen

Tabel 2.

Perhitungan Uji Mann Test, alpha dan beta

\begin{tabular}{cccccc}
\hline No & Nama Komponen & s hitung & s tabel & $\boldsymbol{\alpha}$ & $\boldsymbol{\beta}$ \\
\hline 1 & Pulley Motor & 0.466 & 0.860 & 49.380591 & 2.2803166 \\
\hline 2 & Hydraulic & 0.592 & 0.860 & 43.073354 & 3.1735838 \\
\hline 3 & Bearing Motor & 0.352 & 0.860 & 45.654891 & 4.9038337 \\
\hline 4 & Piston Compressor & 0.539 & 0.860 & 46.578821 & 5.2239113 \\
\hline
\end{tabular}

Tabel 3.

Hasil Rekapitulasi Pergantian Komponen Kritis

\begin{tabular}{ccccccc}
\hline $\mathbf{i}$ & Nama Komponen & $\mathbf{\alpha i}$ & $\boldsymbol{\beta i}$ & $\mathbf{T}(\mathbf{p i})$ & $\mathbf{T}(\mathbf{f i})$ & $\mathbf{T i}^{*}$ (Hari) \\
\hline 1 & Pulley & 49.380591 & 2.2803166 & 0.0475475 & 0.1584918 & 24 \\
\hline 2 & Bearing & 43.073354 & 3.1735838 & 0.0394144 & 0.1313814 & 22 \\
\hline 3 & Hydraulic & 45.654891 & 4.9038337 & 0.0459209 & 0.1530697 & 27 \\
\hline 4 & Piston Compressor & 46.578821 & 5.2239113 & 0.0397898 & 0.1326326 & 28 \\
\hline
\end{tabular}

Dari tabel 3 di atas dapat dilihat dari komponen pulley motor melakukan pergantian setiap 24 hari dan waktu persatu kali pergantian sebesar 0.0475 , bearing 22 hari dan waktu persatu kali pergantian sebesar 0.0394 , hydraulic 27 hari dan waktu persatu kali pergantian sebesar 0.0459 , dan piston compressor 28 hari dengan waktu persatu kali pergantian sebesar 0.0398 . Penentuan jadwal penggantian grup replacement digunakan untuk mengelompokan jadwal dari semua komponen kritis yang telah dihitung sebelumnya. Berikut adalah perhitungan jadwal perawatan group replacement.

$$
\begin{aligned}
\mathrm{H}(\mathrm{tp}) \mathrm{A} & =\left(\frac{t p}{\alpha}\right)^{\beta} \\
& =\left(\frac{16}{49,3806}\right)^{2,2803}
\end{aligned}
$$

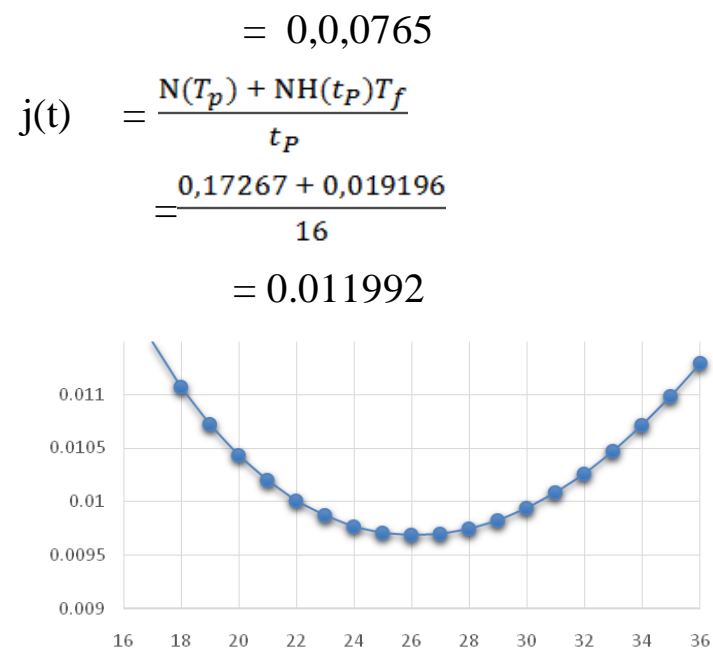

Gambar 4.

Grafik Downtime Perhitungan Grup Replaccement

Dari Gambar 4 diatas dapat terlihat bahwa total waktu penggantian pada 1 kelompok komponen kritis mesin high preassure pump adalah setiap 26 hari. Biaya pemeliharaan 
adalah biaya yang dikeluarkan perusahaan untuk melakukan kegiatan preventive maintenance terhadap komponen kritis mesin high preassure pump. Data yang digunakan diperoleh dari hasil wawancara diperoleh komponen biaya pemeliharaan adalah 1)
Biaya Teknisi Pemeliharaan (BT), 2) Biaya Operator (BO), 3) Biaya Downtime Mesin (BD), 4) Biaya Pembelian Komponen Pengganti (HK).Contoh perhitungan biaya pemeliharaan untuk komponen pulley motor seperti pada Tabel 4.

Tabel 4.

Perhitungan biaya pemeliharaan pencegahan komponen pulley motor

\begin{tabular}{llrrrr}
\hline No & \multicolumn{1}{c}{ Elemen Biaya } & \multicolumn{1}{c}{$\begin{array}{c}\text { Ongkos } \\
\text { Pencegahan }\end{array}$} & \multicolumn{1}{c}{ Tp } & \multicolumn{1}{c}{ Tf } & \multicolumn{1}{c}{$\begin{array}{c}\text { Ongkos } \\
\text { Pencegahan }\end{array}$} \\
\hline 1 & Harga Komponen & 659,250 & 0.0475475 & 0.1584918 & 659,250 \\
\hline 2 & Biaya Teknisi & 179,167 & 0.0475475 & 0.1584918 & 8,519 \\
\hline 3 & Biaya Downtime & $308,676,000$ & 0.0475475 & 0.1584918 & $14,676,787$ \\
\hline 4 & Biaya Operator Menganggur & 179,167 & 0.0475475 & 0.1584918 & 8,519 \\
\hline & Total & & & & $15,353,075$ \\
\hline
\end{tabular}

Tabel 5 adalah hasil rekapitulasi dari biaya pemeliharaan persatu kali pergantian pencegahan komponen kritis high preassure pump.

Tabel 5.

Rekapitulasi Biaya Pemeliharaan

\begin{tabular}{lccccc}
\hline \multicolumn{1}{c}{ Komponen } & BT & BO & BD & HK & TC \\
\hline Pulley Motor & 8,519 & 8,519 & $14,676,787$ & 659,250 & $15,353,075$ \\
\hline Bearing Motor & 7,062 & 7,062 & $12,166,284$ & 575,900 & $12,756,307$ \\
\hline Hydraulic & 8,227 & 8,227 & $14,174,686$ & $1,085,400$ & $15,276,541$ \\
\hline Piston Compressor & 7,129 & 7,129 & $12,282,153$ & 465,000 & $12,761,411$ \\
\hline \multicolumn{3}{c}{ Total } & & $56,147,334$ \\
\hline
\end{tabular}

Biaya pemeliharaan padagrup replacement dilakukan karena data interval penggantian pada komponen kritis mesin high preassure pump saling berdekatan sehingga biaya yang dikeluarkan mengikuti 1 kelompok pergantian komponen.

Tabel 6.

Perhitungan biaya pemeliharaan pencegahan grup replacement

\begin{tabular}{rrrrr}
\hline No & Elemen Biaya & Ongkos Pencegahan & \multicolumn{1}{c}{ Tf } & Ongkos Pencegahan \\
\hline 1 & Harga Komponen & $2,785,550$ & 0.1726727 & $2,785,550$ \\
\hline 2 & Biaya Teknisi & 179,166 & 0.1726727 & 30,937 \\
\hline 3 & Biaya Downtime & $308,676,000$ & 0.1726727 & $53,299,909$ \\
\hline 4 & Biaya Operator Menganggur & 179,166 & 0.1726727 & 30,937 \\
\hline & Total & & $56,147,334$ \\
\hline
\end{tabular}


Maka jika pemeliharaan pencegahan dengan group replacement sebanyak 13 kali dalam 1 tahun, maka total biayanya adalah $\mathrm{Rp}$ 56.147.334 x $13=\operatorname{Rp} 729.915 .346$.

\section{KESIMPULAN}

Setelah melakukan pengamatan, pengumpulan dan pengolahan data, maka simpulan dari penelitian ini adalah:

1. Frekuensi kerusakan dan downtime mesin tertinggi, mesin terpilih yang digunakan dalam penelitian adalah high preassure pump dan pergantian komponen kritis yang dijadwalkan yaitu komponen piston compresor, pulley motor, bearing motor, dan hidraulic.

2. Biaya yang dikeluarkan saat terjadi downtime pada mesin dalam satu hari adalah teknisi pemeliharaan sebesar $\mathrm{Rp}$ 179.167, operator menganggur sebesar $\mathrm{Rp}$ 179.167, biaya downtime sebesar $\mathrm{Rp}$ 308.676.000 dan harga komponen yang akan dijadwalkan yaitu pulley motor sebesar Rp 659.250, bearing sebesar Rp 1.085.400, hydraulic sebsear Rp 575.900 dan piston compressor sebesar $\mathrm{Rp}$ 465.000.

3. Penjadwalan pergantian komponen pulley motor, bearing, hydraulic dan piston compressor akan dilakukan dengan group replacement setiap 26 hari dengan total nilai downtime yang awalnya 3,453 hari menjadi 2,244 hari, sehingga biaya penggantianya sebesar $\mathrm{Rp}$ 729.915.346 per tahun.

\section{DAFTAR PUSTAKA}

[1] Siagian, D. C., Napitupulu, H., Siregar, I. "Usulan Perawatan Mesin Berdasarkan Keandalan Spare Part sebagai Solusi Penurunan Biaya Perawatan pada PT. Xyz," Jurnal Teknik Industri USU, vol. 3, no. 5, 2014.

[2] Utomo, M. N., Widjajati, F. A. "Menentukan Keandalan Komponen Mesin Produksi Pada Model Stress Strength yang Berdistribusi Gamma," Jurnal Sains dan Seni ITS, 3(2), A22-A27, 2014.

[3] Muhammad, Z. A., Edi, H., Nurvita, A. "Perencanaan Pemeliharaan Dan Optimasi Biaya Perawatan Pada Sistem Utility Dengan Metode Preventive Maintenance," In Proceedings Conference on Marine Engineering and its Application Vol. 1, No. 1, pp. 55-60, 2018.

[4] Majid, A. M., Moengin, P., Witonohadi, A. "Usulan Penerapan Total Productive Maintenance (Tpm) Dengan Pengukuran Overall Equipment Effectiveness (Oee) Untuk Perencanaan Perawatan Pabrik Bar Mill Pada PT. Krakatau Wajatama," Jurnal Teknik Industri, vol 4, no. 3), 2014.

[5] Putra, M. A., Marie, I. A. "Rancangan Perawatan Bus Transjakarta Menggunakan Pendekatan Reliability Centered Maintenance di Perum Damri SBU Busway Koridor I \& VIII," Jurnal IImiah Teknik 
Industri, vol. 3, no.3, 2017

[6] Mutiara, S. D., Rahman, A., Hamdala, I. "Perencanaan Preventive Maintenance Komponen Cane Cutter I dengan Pendekatan Age Replacement (Studi Kasus Di Pg Kebon Agung Malang),"
Jurnal Rekayasa dan Manajemen Sistem Industri, vol. 2 no. 2, pp. 396-405, 2014. 